\title{
Differential up-regulation of metallothionein isoforms in well-differentiated nasopharyngeal cancer cells in vitro by photoactivated hypericin
}

\author{
HONG-YAN DU ${ }^{1 *}$, YINGHUI LI ${ }^{1 *}$, MALINI OLIVO ${ }^{2}$, GEORGE WAI-CHEONG YIP ${ }^{1}$ and BOON-HUAT BAY ${ }^{1}$ \\ ${ }^{1}$ Department of Anatomy, National University of Singapore, ${ }^{2}$ Laboratory of Photodynamic \\ Diagnosis and Treatment, National Cancer Centre, Singapore
}

Received June 27, 2006; Accepted August 24, 2006

\begin{abstract}
Photoactivation of hypericin is known to generate reactive oxygen species and induce phototoxic effects. However, modulation of the cellular antioxidant defense would influence the extent and severity of the photodynamic effects. We have previously shown that hypericin-mediated photodynamic therapy (PDT) induced a significant reduction of Glutathione S-transferase activity. In this study, we investigated the phototoxic effects of hypericin-mediated PDT in nasopharyngeal cancer (NPC) in vitro and analyzed the expression of metallothionein (MT), a family of potential free radical scavengers. HK1 NPC cells were subjected to PDT treatment in vitro, and the effects on cell death were analyzed by flow cytometry (using propidium iodide and Annexin V staining) and transmission electron microscopy. The expression profile of MT-1E and MT-2A isoforms (the only functional MT isoforms expressed in HK1 NPC cells) were determined by quantitative real-time RT-PCR. The results showed that hypericin PDT induced necrotic cell death as evidenced by the absence of a subdiploid peak and decreased Annexin- $\mathrm{V}$ fluorescence. Ultrastructural examination verified the presence of cell necrosis. There was a significant up-regulation of MT-1E and MT-2A isoforms six hours following PDT, with an approximately 50-fold rise in the expression level of MT-1E and a 15 -fold increase of MT-2A. Hence, despite the upregulation of $\mathrm{MT}$, cells still succumbed to PDT-induced necrosis. It appears that the oxidative stress induced by PDT overwhelmed the antioxidant defense mechanism such as the alteration of MT levels in tumor cells.
\end{abstract}

Correspondence to: Dr Boon-Huat Bay, Department of Anatomy, Yong Loo Lin School of Medicine, National University of Singapore, 4 Medical Drive, Blk MD10, S117 597, Singapore

E-mail: antbaybh@nus.edu.sg

Dr Malini Olivo, Laboratory of Photodynamic Diagnosis and Treatment, National Cancer Centre, S169 610, Singapore

E-mail:dmsmcd@nccs.com.sg

*Contributed equally

Key words: metallothionein, nasopharyngeal cancer, hypericin

\section{Introduction}

Photodynamic therapy (PDT) is a promising new therapeutic approach for cancer that has been clinically tested for a variety of malignancies $(1,2)$. PDT involves the systemic administration of a tumor-localizing photosensitizer, which is activated via exposure to light of a specific wavelength matching its absorption spectrum. The subsequent generation of reactive oxygen species (ROS) such as singlet oxygen and oxygen free radicals by photodynamic reaction induces oxidative cellular damage, leading to direct tumor cell killing and destruction of tumor tissues. In addition, the tumor cells are also destroyed indirectly by the vascular damage resulting from PDT (3).

The potent anti-neoplastic activity of photosensitizers upon light irradiation has sparked great interest in their potential medical applications in oncology. In particular, hypericin, one of the most powerful natural photosensitizers (4-7) isolated from Hypericum perforatum (St. John's Wort) (8), has been intensively investigated recently for its use as a plausible clinical anticancer drug, owing to its ability to generate a high quantum yield of ROS during photoactivation, with minimal genotoxicity and systemic toxicity (9).

The generation of ROS can induce photooxidative stress and cytotoxicity in PDT-treated cells. However, these photodynamic effects are modulated by cellular antioxidant defense mechanisms such as the up-regulation of intracellular enzymes that have free radical scavenging capabilities. Hypericin-mediated PDT has been reported to affect the activity of antioxidants in cancer cells. In a recent study, we demonstrated that photoactivation of hypericin resulted in a significant reduction of Glutathione S-transferase (GST) activity in HK1 and CNE-2 nasopharyngeal carcinoma (NPC) in vitro and in the tumor tissues of the HK1 NPC murine tumor model as well (10).

Metallothioneins (MTs) belong to a family of potential free radical scavengers which have been implicated in carcinogenesis and chemoresistance. MTs are a group of low molecular weight $(6-7 \mathrm{kDa})$, cysteine-rich intracellular proteins with a strong affinity for heavy metals such as cadmium, mercury, copper and zinc. Since MTs are protein thiols with exceptionally high cysteinyl sulfur content, they have the ability to capture hydroxyl radicals (11). This antioxidant 
property of MTs may be advantageous to tumor cells in their resistance to chemotherapy and radiotherapy $(12,13)$ and presents a major obstacle to the successful eradication and management of various cancers such as nasopharyngeal cancer (NPC). Although there are at least ten known functional MT isoforms, only MT-1E and MT-2A are found in well-differentiated HK1 NPC cells (14). Hence, in the present study, we investigated the phototoxic effects of hypericin-mediated PDT in vitro and further evaluated its effect on the expression profile of MT-1E and MT-2A isoforms in HK1 NPC cells.

\section{Materials and methods}

Preparation of hypericin. A stock solution of hypericin (Molecular Probes, Eugene, OR, USA) was prepared in sterile dimethyl sulfoxide (DMSO) at a concentration of $1 \mathrm{mg} / \mathrm{ml}$ and stored at $-20^{\circ} \mathrm{C}$ in the dark.

Cell culture. Well-differentiated HK1 NPC cells, established from a patient diagnosed with recurrent well-differentiated squamous NPC (15), were grown in RPMI-1640 supplemented with $10 \%$ fetal bovine serum (FBS; Hyclone Logan, UT), $2 \mathrm{mM}$ glutamine, $2 \mathrm{mM}$ sodium pyruvate and $100 \mathrm{unit} / \mathrm{ml}$ penicillin/streptomycin. Cultures were maintained at $37^{\circ} \mathrm{C}$ in a humidified atmosphere of $5 \% \mathrm{CO}_{2}$.

PDT treatment of HK1 NPC cells in vitro. HK1 NPC cells $\left(5 \times 10^{5}\right)$ were seeded into 6-well plates and incubated overnight at $37^{\circ} \mathrm{C}$ in complete growth media. Subsequently, 0-2 $\mu \mathrm{M}$ hypericin was added and the cells were incubated for $4 \mathrm{~h}$ under subdued light conditions. Cells were then irradiated in hypericin-free medium at a dose of $0.5 \mathrm{~J} / \mathrm{cm}^{2}$. A bank of fluorescence tubes (Phillips, type OSRAM L30w11-860, $30 \mathrm{~W}$ ) filtered with red acetate filters (no. 17, Roscolux, Rosco, CA, USA) was used to produce a wide-band illumination $>585 \mathrm{~nm}$.

Measurement of cellular DNA content with propidium iodide (PI) staining. HK1 NPC cells were harvested for $4 \mathrm{~h}$ following irradiation and re-suspended in $1 \mathrm{ml}$ PBS containing $1 \mathrm{mg} / \mathrm{ml}$ ribonuclease (type-1A, Sigma) and $50 \mu \mathrm{g} / \mathrm{ml}$ PI (Sigma). Cells were kept on ice in the dark and the fluorescence was measured on a linear scale using a FACScan flow cytometer (Becton Dickinson, Mountain View, CA) equipped with an exciting laser line at $488 \mathrm{~nm}$ and a $575 \pm 15-\mathrm{nm}$ band-pass filter. A minimum of 10,000 events were collected for each sample and the data was analyzed using CellQuest software (Becton Dickinson).

Measurement of phosphatidylserine (PS) expression using fluorescein isothiocyanate (FITC)-labeled Annexin V. HK1 NPC cells collected $4 \mathrm{~h}$ after light treatment were analyzed for Annexin V binding and PI uptake by flow cytometry, using the ApoAlert ${ }^{\mathrm{TM}}$ Annexin V-FITC apoptosis kit (Clontech, Palo Alto, CA), according to the manufacturer's instructions. The cells were re-suspended in $200 \mu 1$ of binding buffer (provided in the kit) and $5 \mu \mathrm{l}$ of the Annexin V stock solution and $10 \mu 1$ of PI stock solution were then added to the cell suspension for a final concentration of $1 \mu \mathrm{g} / \mathrm{ml}$. After $10 \mathrm{~min}$ of incubation in the dark, cells were immediately analyzed with the FACScan flow cytometer. The FITC-Annexin V and a

Untreated

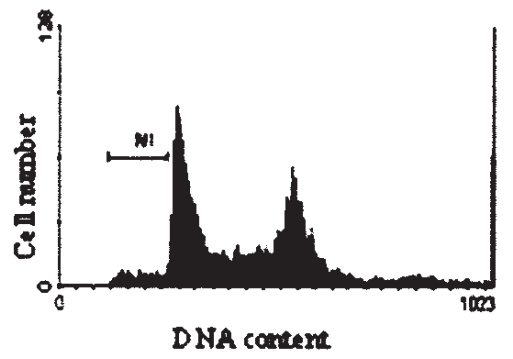

C

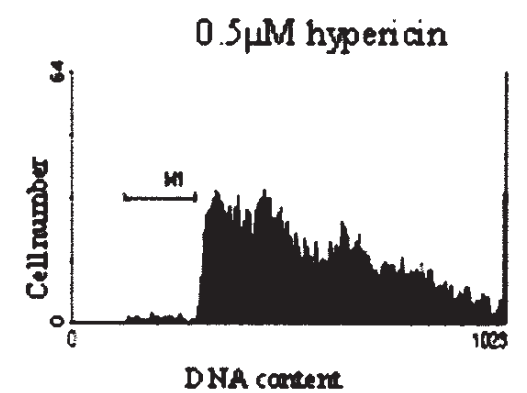

b

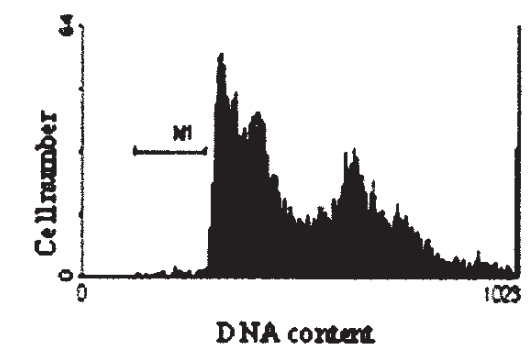

$d$

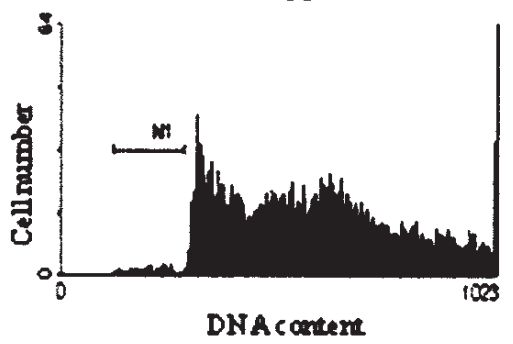

Figure 1. Hypericin-PDT induced cell death in HK1 cells analyzed by PI staining using flow cytometry. HK1 cells were incubated with 0 - $1 \mu$ M hypericin for $4 \mathrm{~h}$ followed by light irradiation of $0.5 \mathrm{~J} / \mathrm{cm}^{2}$. Cell death was analyzed $4 \mathrm{~h}$ post PDT. Cells were stained with PI for DNA content analysis. Representative plots are shown: (a) untreated cells; (b) hypericin, $0.25 \mu \mathrm{M}$; (c) hypericin, $0.5 \mu \mathrm{M}$; and (d) hypericin, $1 \mu \mathrm{M}$. 
Table I. Primers for real-time PCR.

\begin{tabular}{llr}
\hline Gene & \multicolumn{1}{c}{ Primer sequences } & Product size \\
\hline$M T-1 E$ & Forward 5' GCTTGTTCGTCTCACTGGTG 3' & 284 bp \\
& Reverse 5' CAGGTTGTGCAGGTTGTTCTA 3' \\
$M T-2 A$ & Forward 5' CCGACTCTAGCCGCCTCTT 3' & 259 bp \\
& Reverse 5' GTGGAAGTCGCGTTCTTTACA 3'
\end{tabular}

PI fluorescence were collected on a log scale through a $530 \pm 20$ - and 575 \pm 15 -nm band-pass filter respectively.

Transmission electron microscopy. Following PDT treatment, HK1 NPC cells grown in a chambered coverglass (Lab-Tek, IL, USA) were fixed with $2 \%$ paraformaldehyde and $3 \%$ glutaraldehyde in $0.1 \mathrm{M}$ phosphate buffer ( $\mathrm{pH} 7.4$ ) for $30 \mathrm{~min}$, followed by osmication in $1 \%$ osmium tetroxide. Specimens were subsequently dehydrated and infiltrated with increasing strengths of araldite/acetone mixtures and the slides were then placed in a $60^{\circ} \mathrm{C}$ oven for $24 \mathrm{~h}$ to allow polymerization to take place. Ultra-thin sections were cut using the ultramicrotome and mounted on a formvar-coated grid, followed by double staining with lead citrate and uranyl acetate before examination under a Philips CM 120 transmission electron microscope.

Quantitative real-time polymerase chain reaction (PCR). At selected time intervals, HK1 cells and tumor tissues were harvested for the extraction of total RNA with an RNeasy mini kit (Qiagen), according to the manufacturer's protocol. Real-time PCR was performed with the Light Cycler system (Roche), using the QuantiTect SYBR-Green PCR kit (Qiagen). Complementary DNA (cDNA) synthesized from $2 \mu \mathrm{g}$ of DNA-free total RNA was used at a final dilution ratio of $1: 10$ as the template for RT-PCR analysis. The primers used for the detection of MT-1E and MT-2A isoforms, adapted from Middidodi et al (16), are shown in Table I and the housekeeping gene was $\beta$-actin.

Statistical analyses. The Graphpad Prism statistical package was used for statistical analysis. One-way ANOVA with a post hoc Tukey test was used to compare variables. $\mathrm{P}<0.05$ was considered to be statistically significant.

\section{Results}

PDT treatment induced necrosis in HKl cells. As shown in Fig. 1, no subdiploid peak was detected in HK1 cells after hypericin incubation followed by light irradiation, indicating

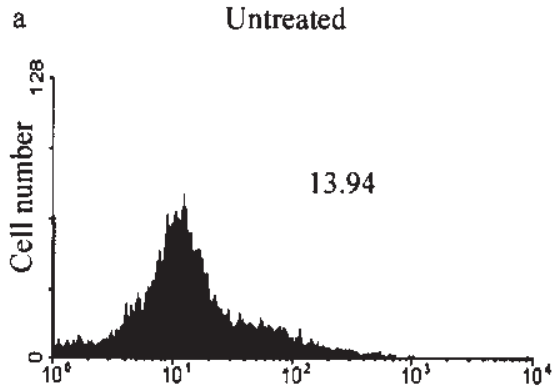

Ann-V

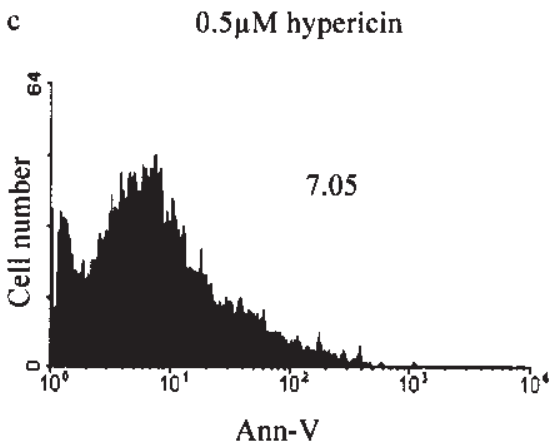

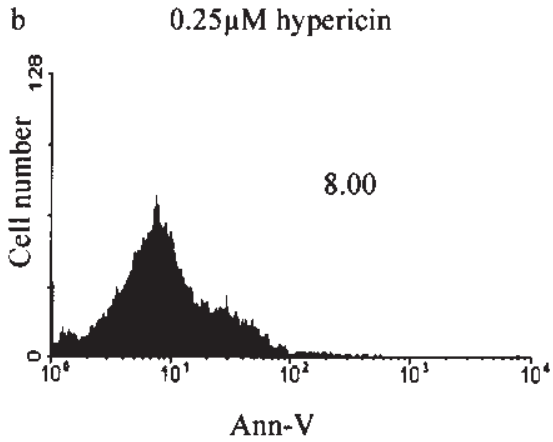

d

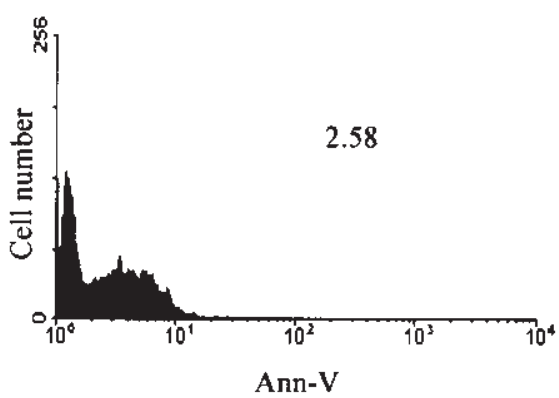

Figure 2. Hypericin-PDT induced cell death in HK1 cells analyzed by Annexin V staining using flow cytometry. HK 1 cells were incubated with 0-1 $\mu$ M hypericin for $4 \mathrm{~h}$ followed by light irradiation of $0.5 \mathrm{~J} / \mathrm{cm}^{2}$. Cell death was analyzed $4 \mathrm{~h}$ post PDT. Cells were stained with Annexin $\mathrm{V}$ to assess PS externalization. Numbers represent relative fluorescence of Annexin V. Representative plots are shown: (a) untreated cells; (b) hypericin, $0.25 \mu \mathrm{M}$; (c) hypericin, $0.5 \mu \mathrm{M}$; and (d) hypericin, $1 \mu \mathrm{M}$. 

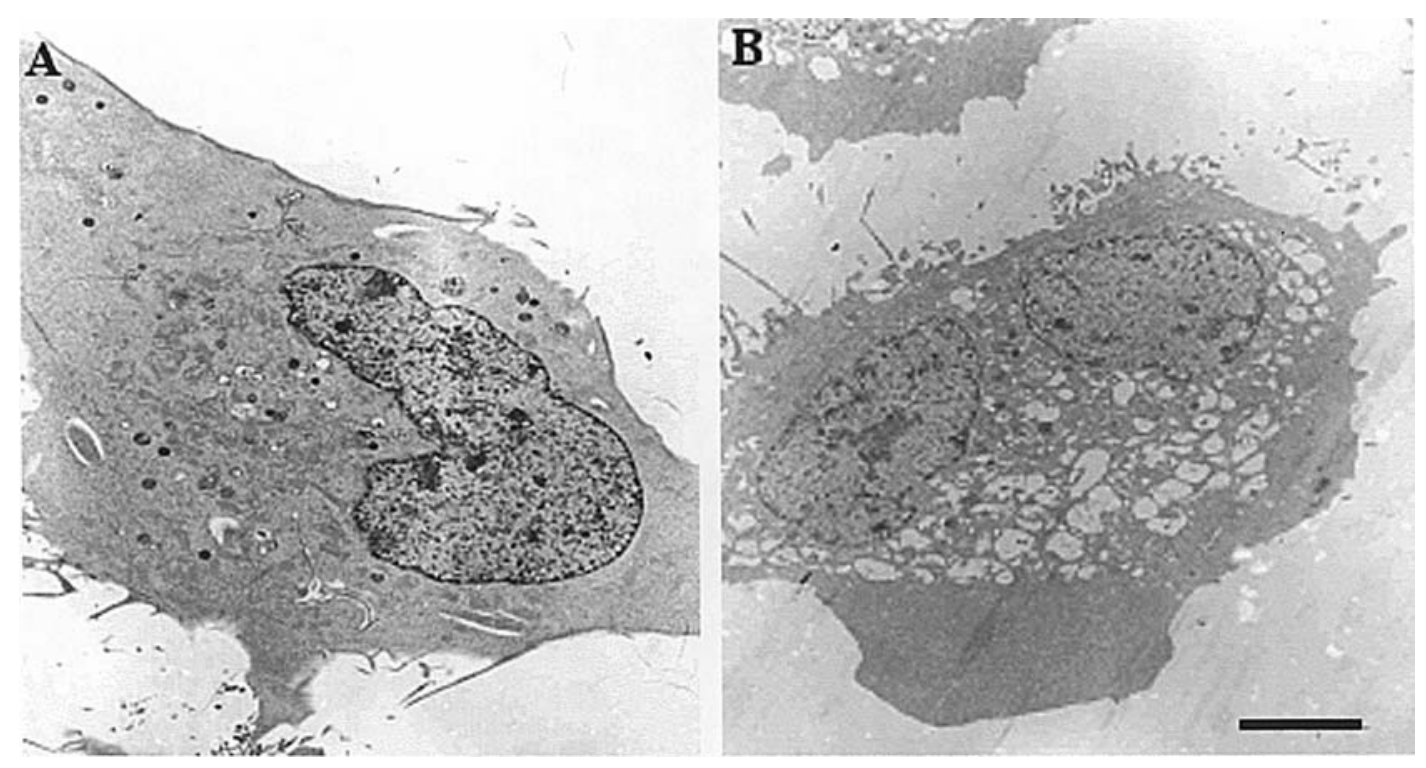

Figure 3. Electron micrograph of necrotic HK1 cells. (A) Untreated cell, (B) PDT-treated cell exhibiting cytoplasmic vacuolization. Bar $=5 \mu \mathrm{m}$.

the absence of apoptosis. The fluorescence of Annexin- $\mathrm{V}$ was observed to decrease, probably as a result of the loss of integrity of the cell membrane due to necrosis (Fig. 2). On the other hand, in cell death induced by apoptotic pathways, plasma membrane phosphatidylserine (PS), an early marker of apoptosis, translocates from the inner layer to the outer layer of the plasma membrane and binds to Annexin $\mathrm{V}$, giving rise to increased fluorescence. The necrotic mode of cell death induced by hypericin-mediated PDT in HK1 cells was further verified by transmission electron microscopy. Ultrastructural examination revealed vacuolization of cytoplasm without nuclear change or chromatin condensation (Fig. 3).

Effect of hypericin on metallothionein expression in HKI cells. Treatment of HK1 cells with $0.5 \mu \mathrm{M}$ hypericin induced a significant change in the expression of both metallothionein isoforms $\left(\mathrm{P}<0.0001\right.$; Table II). The $\Delta \Delta \mathrm{C}_{\mathrm{T}}$ values of MT-1E and MT-2A after $6 \mathrm{~h}$ were statistically significant when compared to controls $(\mathrm{P}<0.01)$. There was a near 50 -fold rise in the expression level of MT-1E while that of MT-2A increased by 15 -fold after $6 \mathrm{~h}$, which subsequently declined to normal levels by the 25 th hour of PDT (Table II).

\section{Discussion}

Hypericin-PDT has been documented for the treatment of skin cancer and in clinical studies of recurrent mesothelioma in the past decade $(17,18)$. PDT has also been investigated as an alternative therapeutic modality in NPC, a biologically distinct form of head and neck cancer with a multifactorial etiology, consisting of genetic, viral and environmental factors. While the use of radiotherapy and chemotherapy in the treatment of NPC has been associated with systemic toxicity and a poor 5-year overall survival rate owing to high recurrence rates, the use of PDT in the palliative management of recurrent NPC has been encouraging and has been found to improve the survival rate of NPC patients $(19,20)$.

Photoactivation of hypericin has been demonstrated to produce superoxide anion $\left(\mathrm{O}_{2}^{-}\right)$(type I process) and a high quantum yield of singlet oxygen $\left({ }^{1} \mathrm{O}_{2}\right)$ (type II process) (4). Superoxide anion radicals further initiate the generation of hydrogen peroxide $\left(\mathrm{H}_{2} \mathrm{O}_{2}\right)$ and hydroxyl $\left(\mathrm{OH}^{-}\right)$radicals (4). Recently, we demonstrated that hypericin-mediated PDT induced tumor necrosis and lipid peroxidation in the welldifferentiated NPC/HK1 murine tumor model, thereby leading

Table II. Mean $\Delta \mathrm{C}_{\mathrm{T}}$ and $\Delta \Delta \mathrm{C}_{\mathrm{T}}$ values of MT-2A and MT-1E isoforms in HK1 cells.

\begin{tabular}{lcccc}
\hline Sample type & \multicolumn{2}{c}{ MT-2A } & \multicolumn{2}{c}{ MT-1E } \\
\cline { 2 - 5 } & $\begin{array}{c}\text { Mean } \Delta \mathrm{C}_{\mathrm{T}} \pm \mathrm{SD} \\
(\mathrm{n}=3)\end{array}$ & $\begin{array}{c}\text { Mean } \Delta \Delta \mathrm{C}_{\mathrm{T}} \pm \mathrm{SD} \\
(\mathrm{n}=3)\end{array}$ & $\begin{array}{c}\text { Mean } \Delta \mathrm{C}_{\mathrm{T}} \pm \mathrm{SD} \\
(\mathrm{n}=3)\end{array}$ & $\begin{array}{c}\text { Mean } \Delta \Delta \mathrm{C}_{\mathrm{T}} \pm \mathrm{SD} \\
(\mathrm{n}=3)\end{array}$ \\
\hline Control & $4.14 \pm 0.34$ & $0.00 \pm 0.34$ & $4.36 \pm 0.62$ & $0.00 \pm 0.62$ \\
PDT-treated 1 h & $4.42 \pm 0.33$ & $0.28 \pm 0.33$ & $4.79 \pm 0.23$ & $0.43 \pm 0.23$ \\
PDT-treated 4h & $4.47 \pm 0.07$ & $0.33 \pm 0.07$ & $3.61 \pm 0.45$ & $-0.74 \pm 0.45$ \\
PDT-treated 6 h & $0.26 \pm 0.32$ & $-3.88 \pm 0.32$ & $-1.27 \pm 0.47$ & $-5.63 \pm 0.47$ \\
PDT-treated 25 h & $4.52 \pm 0.45$ & $0.37 \pm 0.45$ & $4.51 \pm 0.31$ & $0.15 \pm 0.31$ \\
P value & $<0.0001$ & & $<0.0001$ & \\
\hline
\end{tabular}


to tumor shrinkage and regression $(21,22)$. In the present study, we demonstrated that the photoactivation of hypericin elicited necrosis in HK1 NPC cells in vitro via transmission electron microscopy and Annexin V staining by flow cytometry, reaffirming the potent anti-tumor properties of PDT. In addition, there was a significant up-regulation of both MT-1E and MT-2A expression following light irradiation in the hypericin-treated HK1 cells, suggesting a response by the tumor cells to resist PDT-induced cell death via the increased production of MT isoforms, which can act as free radical scavengers.

MT expression is induced by a variety of stimuli ranging from metals, hormones, cytokines, inflammation, and stress $(23,24)$. In humans, heavy metals such as cadmium and zinc have the ability to induce the expression of all the MT isoforms, with the specific type of isoform induced, as well as the rate, extent and duration of MT mRNA transcript accumulation being dependent on the metal inducer and cell type involved $(25,26)$. In humans, glucocorticoids can only induce the expression of MT-2A and MT-1E isoforms, thus demonstrating the independent regulation of human MT isoforms (27). There are several lines of evidence suggesting the critical role of MT isoforms in various aspects of carcinogenesis, including malignant transformation, treatment resistance and prognosis of human tumors $(28,29)$. The ability of MTs to bind heavy metals such as zinc is potentially advantageous for the growth and survival of tumors (30). Moreover, the antioxidant or free radical scavenging property of MTs may be vital to cancerous cells in counteracting ROS and other cytotoxic agents released by the body's immune cells during the initial stages of transformation or generated during therapeutic intervention. Metallothionein has also been found to exhibit a protective effect during conditions of oxidative stress, such as radiation-induced DNA damage $(31,32)$.

Increased MT-1 and MT-2 mRNA expression in lightdamaged mouse retina suggests that up-regulation of MT is an important acute retinal response to photooxidative stress (33). MT-2A expression has recently been reported to protect against ROS-mediated cell death in rotenone-treated HeLa cells (34). The concomitant induction of MT-1E and MT-2A overexpression at six hours after hypericin-mediated PDT in HK-1 cells supports the antioxidant role of MT isoforms. To the best of our knowledge, this is the first study reporting that PDT increases the expression of MT-1E and MT-2A isoforms. The up-regulation of MT may pose a major barrier to the efficacy of PDT treatment. However, it is still unclear as to why there is a higher increase in the MT-1E isoform expression compared to that of MT-2A.

In the present study, it was interesting to note that photoactivation of hypericin triggered necrosis of welldifferentiated HK-1 cells despite the up-regulation of MT-1E and MT-2A. This finding suggests that the hypericin PDT treatment administered was able to induce an oxidative stress which overwhelmed the antioxidant defense mechanism such as the up-regulation of MT in the tumor cells. Furthermore, previous studies documenting the effects of hypericinmediated PDT on HK-1/NPC tumors in vivo have also produced promising findings $(20,21)$. Hence, hypericinmediated PDT shows great potential as a plausible alternative therapeutic strategy for nasopharyngeal cancer.

\section{Acknowledgements}

The HK1 NPC cell line was kindly provided by Professor Hui Kam Man, National Cancer Centre. The authors are grateful to Yajun Wu for technical assistance. This research project was sponsored by the National Medical Research Council and Academic Research Fund (National University of Singapore).

\section{References}

1. Dougherty TJ: An update on photodynamic therapy applications. J Clin Laser Med Surg 20: 3-7, 2002.

2. Dolmans DE, Fuumura D and Jain RK: Photodynamic therapy for cancer. Nat Rev Cancer 3: 380-387, 2003.

3. Fingar VH: Vascular effects of photodynamic therapy. J Clin Laser Med Surg 14: 323-328, 1996.

4. Agostinis P, Vantieghem A, Merlevede W and de Witte PA: Hypericin in cancer treatment: more light on the way. Int $\mathrm{J}$ Biochem Cell Biol 34: 221-241, 2002.

5. Redmond RW and Gamlin JN: A compilation of singlet oxygen yields from biologically relevant molecules. Photochem Photobiol 70: 391-475, 1999.

6. Jacobson JM, Feinman L, Liebes L, Ostrow N, Koslowski V, Tobia A, Cabana BE, Lee D, Spritzler J and Prince AM: Pharmacokinetics, safety, and antiviral effects of hypericin, a derivative of St. John's wort plant, in patients with chronic hepatitis $C$ virus infection. Antimicrob Agents Chemother 45: 517-524, 2001.

7. Fox E, Murphy RF, McCully CL and Adamson PC: Plasma pharmacokinetics and cerebrospinal fluid penetration of hypericin in nonhuman primates. Cancer Chemother Pharmacol 47: 41-44, 2001.

8 Duran N and Song PS: Hypericin and its photodynamic action. Photochem Photobiol 43: 677-680, 1986.

9. Meruelo D, Lavie G and Lavie D: Therapeutic agents with dramatic antiretroviral activity and little toxicity at effective doses-aromatic polycyclic diones hypericin and pseudohypericin. Proc Natl Acad Sci USA 85: 5230-5234, 1988.

10. Du HY, Olivo M, Tan BKH and Bay BH: Photoactivation of hypericin down-regulates glutathione S-transferase activity in nasopharyngeal cancer cells. Cancer Lett 207: 175-181, 2004.

11. Sato $M$ and Kondoh $M$ : Recent studies on metallothionein: protection against toxicity of heavy metals and oxygen free radicals. Tohoku J Exp Med 196: 9-22, 2002.

12. Bakka A, Endresen L, Johnson ABS, Edminson PD and Rugstad HE: Resistance against cisplatin in cultured cells with high content of metallothionein. Toxicol Appl Pharmacol 61: 215-226, 1981.

13. Satoh M, Cherian MG, Imura N and Shimizu H: Modulation of resistance to anticancer drugs by inhibition of metallothionein synthesis. Cancer Res 54: 5255-5257, 1994.

14. Tan OJK, Bay BH and Chow VTK: Differential expression of metallothionein isoforms in nasopharyngeal cancer and inhibition of cell growth by antisense down-regulation of metallothionein-2A. Oncol Rep 13: 127-131, 2005.

15. Huang DP, Ho JH, Poon YF, Chew EC, Saw D, Lui M, Li CL, Mak LS, Lai SH and Lau WH: Establishment of a cell line (NPC/HK1) from a differentiated squamous carcinoma of the nasopharynx. Int J Cancer 26: 127-132, 1980.

16. Mididoddi S, McGuirt JP, Sens MA, Todd JH and Sens DA: Isoform-specific expression of metallothionein mRNA in the developing and adult human kidney. Toxicol Lett 685: 17-27, 1996.

17. Alecu M, Ursaciuc C, Halalau F, Coman G, Merlevede W, Waelkens E and de Witte P: Photodynamic treatment of basal cell carcinoma and squamous cell carcinoma with hypericin. Anticancer Res 18: 4651-4654, 1998.

18. Koren H, Schenk GM, Jindra RH, Alth G, Ebermann R, Kubin A, Koderhold G and Kreitner M: Hypericin in phototherapy. J Photochem Photobiol B 36: 113-119, 1996.

19. Daoud J and Frikha M: Carcinoma of the nasopharynx, radiotherapy modalities and combined radiotherapy and chemotherapy: state of the art and perspective. Cancer Radiother 5 (suppl 1): 195-200, 2001.

20. Tong MC, van Hasselt CA and Woo JK: Preliminary results of photodynamic therapy for recurrent nasopharyngeal carcinoma. Eur Arch Otorhinolaryngol 253: 189-192, 1996. 
21. Du H, Bay BH and Olivo M: Biodistribution and photodynamic therapy with hypericin in a human murine tumor model. Int J Oncol 22: 1019-1024, 2003.

22. Du H, Olivo M, Tan BKH and Bay BH: Hypericin-mediated photodynamic therapy induces lipid peroxidation and necrosis in nasopharyngeal cancer. Int J Oncol 23: 1401-1405, 2003.

23. Miles AT, Hawksworth GM, Beattie JH and Rodilla V: Induction, regulation, degradation, and biological significance of mammalian metallothioneins. Crit Rev Biochem Mol Biol 35: 35-70, 2000.

24. Coyle P, Philcox JC, Carey LC and Rofe AM: Metallothionein: The multipurpose protein. Cell Mol Life Sci 59: 627-647, 2002.

25. Sadhu $\mathrm{C}$ and Gedamu L: Regulation of human metallothionein (MT) genes. Differential expression of MTI-F, MTI-G, and MTII-A genes in the hepatoblastoma cell line (HepG2). J Biol Chem 263: 2679-2684, 1988.

26. Jahroudi N, Foster R, Price-Haughey J, Beitel G and Gedamu L: Cell-type specific and differential regulation of the human metallothionein genes. Correlation with DNA methylation and chromatin structure. J Biol Chem 265: 6506-6511, 1990.

27. Gedamu L, Foster R, Jahroudi N, Samson SL, Shworak NW and Zafarullah M: Regulation of human and rainbow trout metallothionein genes. In: Metallothionein III: Biological Roles and Medical Implications. Suzuki KT, Imura N and Kimura M (eds). Berkhäuser Verlag, Basel, pp365-382, 1993.
28. Cherian MG, Howell SB, Imura N, Klaassen CD, Koropatnick J, Lazo JS and Waalkes MP: Role of metallothionein in carcinogenesis. Toxicol Appl Pharmacol 126: 1-5, 1994.

29. Theocharis SE, Margeli AP, Klijanienko JT and Kouraklis GP: Metallothionein expression in human neoplasia. Histopathology 45: 103-118, 2004.

30. Cherian MG, Jayasurya A and Bay BH: Metallothioneins in human tumors and potential roles in carcinogenesis. Mut Res 533: 201-209, 2003.

31. Thornalley PJ and Vasák M: Possible role for metallothionein in protection against radiation-induced oxidative stress. Kinetics and mechanism of its reaction with superoxide and hydroxyl radicals. Biochim Biophys Acta 827: 36-44, 1985.

32. Cai L and Cherian MG: Zinc-metallothionein protects from DNA damage induced by radiation better than glutathione and copper- or cadmium- metallothioneins. Toxicol Lett 136: 193-198, 2003.

33. Chen L, Wu W, Dentchev T, Wong R and Dunaief JL: Increased metallothionein in light damaged mouse retinas. Exp Eye Res 79: 287-293, 2004.

34. Reinecke F, Levanets O, Olivier Y, Louw R, Semete B, Grobler A, Hidalgo J, Smeitink JA, Olckers A and van der Westhuizen FH: Metallothionein-2A expression is inducible and protects against ROS-mediated cell death in rotenone treated HeLa cells. Biochem J 395: 405-415, 2006. 